
\title{
25 Research Square \\ Climate Change and More Disturbed Land-Use Types will Further the Invasion of a Non-Native Annual Grass, Ventenata Dubia
}

Arjun Adhikari ( $\nabla$ aadhikari@gmail.com )

Collin College - Plano Campus https://orcid.org/0000-0002-4698-1700

Jane Mangold

Montana State University Bozeman

Lisa J. Rew

Montana State University Bozeman

\section{Research Article}

Keywords: Invasive weeds, SDM, agriculture land, developed land

Posted Date: July 9th, 2021

DOl: https://doi.org/10.21203/rs.3.rs-533398/v1

License: (우 (i) This work is licensed under a Creative Commons Attribution 4.0 International License. Read Full License 


\section{Abstract}

Many land uses are highly prone to invasion of new non-native plant species under changing climate. Identification of suitable habitat for invasive weeds and their projected infestation extent across different land use cover types under a changing climate is crucial for the broad management goals of prevention, detection, and rapid response. In this study, we adopted an ensemble approach of species distribution models to project potential habitat of the invasive annual grass, Ventenata dubia, along the road corridor of Gallatin county, Montana, USA, under current and future climates. The model prediction of $V$. dubia habitat was excellent. The climate predictors most correlated with $V$. dubia occurrence were precipitation, potential evapo-transpiration, relative humidity, vapor pressure deficit, and solar radiation for months during the growing season, and fall germination. The model projected 1,945 and $7,374 \mathrm{~km}^{2}$ under RCP4.5, and 2,306 and $11,050 \mathrm{~km}^{2}$ for road corridors and Gallatin county, respectively. We found that the projected increases in V. dubia infestations were highest for road corridors (239\% under RCP4.5 and $302 \%$ under RCP8.5) compared to that of Gallatin County (127\% under RCP4.5 and $241 \%$ under RCP8.5). Among the land class types, the model projected greatest expansion of $V$. dubia cover across agriculture land with $425 \%$ and $484 \%$ and grassland with $278 \%$ and $442 \%$ increase under RCP4.5 and RCP8.5, respectively. We conclude that $V$. dubia with a short history of invasion is expanding at an alarming rate challenging the status quo and requires greater investment in detection and monitoring to prevent further expansion.

\section{Introduction}

Invasive weeds are of global concern and are often spread along transportation networks (Hulme 2009). Seeds attached to vehicles can travel hundreds of kilometers before falling off (Taylor et al. 2012). Consequently, national roads where vehicles are likely driving longer distances and between regions have nearly double the richness and abundance of non-native species than secondary roads (Vakhlamova et al. 2016). However, the success of such movements depends on the environmental suitability at the new location, and those that establish become the primary source of invasion into adjacent agricultural and wild lands, adversely impacting agriculture production and ecological processes (Dostálek et al. 2016). Understanding the environmental requirements of new invaders can be used to predict where a species is likely to occur now and under global change.

Road corridors provide a more similar environment throughout their length than with adjacent habitats, such that they can be considered a separate habitat (Lugo and Gucinski 2000). Road construction results in homogeneous substrates, and roadside maintenance alters light availability; soil texture, compaction and chemistry; and increases water runoff along the road corridor (Spellerberg 1998), all of which effect the vegetation (e.g. Gelbard and Belnap 2003; McDougall et al. 2018; Seipel et al. 2012). Disturbance of roadsides due to maintenance and other activities (e.g. off-road driving, emergency uses, fire), removes vegetation and creates open gaps with more light and other resources than undisturbed areas. Typically, plants that invade roadsides are expected to be ruderal, short-lived species that use resources very efficiently (McDougall et al. 2018). For instance, (Šerá 2010) found that primary roads in the Czech Republic were indeed dominated by annual species with a ruderal life strategy. 
Ventenata dubia (Leers) Coss. (ventenata, North Africa grass) is a winter annual grass, native to southern Europe and northern Africa, and a relatively recent invasive species to the north-western United States of America (Jones et al. 2018). It was first recorded across grasslands in Washington and Idaho in the 1950's and has spread along roadways and into sagebrush steppe and Palouse prairie rangelands, pastures primarily Phleum pratense L. - hay fields, winter grain and conservation reserve program land throughout the inland Pacific Northwest and into the Northern Great Plains (Northam and Callihan 1992; Wallace et al. 2015). It was first documented in Montana in the 1990's and is now reported in 18 Montana counties, occurring along roadsides, pastures and rangeland (Harvey et al. 2020). V. dubia was designated as a high priority noxious weed in Montana in 2019, meaning that it is targeted for "eradication and containment" and a better understanding of the species' biology, ecology, and management is required (Harvey and Mangold 2019).

$V$. dubia is likely spread by vehicles travelling along roadways and through infested hay. Since this species is still relatively new to the region, little information has been published about its habitat niche and distribution potential. In the Pacific Northwest it was first observed in wetter sites but has spread to drier habitats over the last 30 years (Jones et al. 2020). Species distribution modeling (SDM) is a well-established technique to evaluate climate and environmental requirements of a species, and project the potential habitat range for the species of interest. The technique has become an essential tool in ecology, biogeography, species conservation and natural resource management (Adhikari et al. 2019b; Franklin 2013; Guisan and Thuiller 2005). Species distribution modelling can also be used to help prioritize management, by identifying areas to survey for the target species and to monitor for effectiveness of management (Rew et al. 2007). Overall, the goal of this research was to determine the climate and land use most suitable for $V$. dubia to help inform management of this species. Specifically, our study aimed to 1) identify the main climate factors that control the distribution of $V$. dubia, 2) quantify projected spatial extent of suitable habitat along road corridors and the general landscape under current and future climate scenarios, 3) compare the susceptibility of the roadsides and other land uses to invasion by $V$. dubia, and 4) quantify projected cover of $V$. dubia in different land use class types. Our study is based in Gallatin County, Montana, USA. We surveyed for V. dubia along roadsides and our results will provide a basis for our county, and adjacent ones, to strategize county-wide management of $V$. dubia.

\section{Methods}

Gallatin County $\left(6,820 \mathrm{~km}^{2}\right)$ is our study area, consisting of sweeping valleys and mountain ridges in southwest Montana within the Rocky Mountains (Fig. 1). The county is intertwined by a 1,226 km long road network (paved and unpaved). There are a mix of land uses including crop production, rangeland and forests with a mix of private and public land ownerships. The area is characterized by a semiarid, continental type of climate with cold winters and mild warm summers at high elevation. There are considerable climatic differences across the county due to the elevation range $(1,234-3,199 \mathrm{~m})$ and varying topography. The main city, and initial focus point for this research is Bozeman (-110.05 W, $45.6835 \mathrm{~N})$ at an elevation of $1463 \mathrm{~m}$. The 30-year average climate for Bozeman consists of a high temperature of $13.9 \mathrm{C}$ and minimum of $-0.6 \mathrm{C}$, with $429 \mathrm{~mm}$ of precipitation (US Climate 2021). 


\section{Roadside survey for Ventenata dubia}

We surveyed for $V$. dubia along main and major connector roads (federal, state, and county) from Bozeman to the county line in all directions. The surveyed area started in Bozeman as this was the site of previously known infestations. The survey protocol entailed field data collection by a team of two, a driver and an observer who drove at slow speeds (3.2-16.1 kph) along both edges of a road. A global positioning system (GPS) was used to collect information on $V$. dubia occurrence (abundance categories) along the road corridor. Both sides of $182 \mathrm{~km}$ of roads were recorded for a total observed distance of $364 \mathrm{~km}$. The same roads were surveyed in 2019 and 2020 to allow for annual variability in climate and plant occurrence. Surveying took place over 10 days in 2019 (July 12, 16, 19, 26, 30 and August 1, 5, 6,7 and 8), and 12 days in 2020 (Monday-Thursday July 13-30). The data were converted to presence/absence for $10 \mathrm{~m}$ sections of roadside, and if $V$. dubia was observed in a location in either year it was considered a presence. A total of 467 presence records $(10 \mathrm{~m})$ were recorded along the surveyed roads (Fig. 1).

\section{Climatic and environmental predictors of Ventenata dubia distribution}

Climate variables from Multivariate Adaptive Constructive Analogs (MACA) products at $4 \mathrm{~km}$ spatial resolution were used to project habitat suitability of $V$. dubia in this study. Variables included monthly average minimum and maximum temperatures, precipitation, potential evapotranspiration (PET), vapor pressure deficit (VPD), relative humidity (RH), and solar radiation (SR). The MACA products were derived by a statistical downscaling method and calibrated with observed meteorological dataset (i.e. training dataset) to make compatible spatial patterns after correcting historical biases (Abatzoglou, Brown 2012). The $4 \mathrm{~km}$ spatial data were then statistically downscaled to $1 \mathrm{~km}$ spatial resolution. These historic climate data were summarized as the monthly average for the period of 1980-2006. In addition to the climatic variables, we used available soil water holding capacity (ASWHC) and percent sand (Miller and White 1998) as other environmental predictors.

\section{Collinearity analysis}

We considered eighty-six climate and environmental predictors for constructing the SDM. Collinearity of predictors was assessed by Pearson's correlation coefficient to minimize multi-collinearity issues with low value $(r<0.70)$ (Dormann et al. 2007). Highly collinear predictors do not uniquely contribute to the model, but such collinearity among predictors can be problematic when assessing significance of individual parameters. Therefore, we eliminated highly correlated predictors from the initial sets of environmental variables. During the model development, we selected only one variable from each pair of correlated variables which was based on ecological knowledge of a species' relationship with its environment. In total 14 uncorrelated variables were retained.

\section{Future climate data}

To understand how $V$. dubia distribution could be impacted by climate change, we adopted climate change scenarios with the same sets of future (2011 to 2040) environmental predictors as in the historical period (1981 to 2005) but projected by a general circulation model (GCM). The scenarios were generated from the 
experiments conducted under the fifth assessment of Coupled Model Intercomparison Project Phase 5 (CMIP5) for the Intergovernmental Panel on Climate Change (IPCC). The climate change scenarios include a medium (RCP4.5) and high (RCP8.5) representative concentration pathway from 2011 to 2040 . The medium and high scenarios represent the amount of anthropogenic forcing, $4.5 \mathrm{~W} / \mathrm{m}^{2}$ and $8.5 \mathrm{~W} / \mathrm{m}^{2}$ respectively, consistent with increases in atmospheric greenhouse gases at current rates (Moss et al. 2010). Climate predictors for the future period from 2011-2040 were averaged from a warm and dry climate scenario predicted by CCSM4 GCM. The CCSM4 moderately captures overall spread of future projections of temperature and precipitation changes across the study area (Adhikari et al. 2019a).

\section{Modeling approach, evaluation and analysis}

We selected algorithms for five models within an ensemble framework to create a bioclimatic niche model of $V$. dubia for the current and future scenarios using Biomod2 software programmed in R environment (Thuiller et al. 2016). The models included Generalized Linear Models, Random Forest (Magness et al. 2008; Prasad et al. 2006), Artificial Neural Network (ANN, Olden et al. 2008), classification tree analysis (CRT, Breiman 2017), and Flexible Discriminant Analysis (HDA, Hastie et al. 1994). The ensemble model output considered the mean suitable value for each route.

The accuracy of the model was assessed from the data generated by the split-sample. The data were randomly split in a ratio so that $80 \%$ of the data were used for model development and $20 \%$ for model evaluation with 3-fold cross-validation (Thuiller et al. 2016). We used the area under the curve values (AUC) of receiver operator characteristic (ROC) curves to assess the model performance. The model evaluation methods inherit different weights to multiple prediction errors such as omission, commission or confusion. A model with the AUC value $<0.70$ is considered poor, $0.7-0.9$ considered moderate, and $>0.9$ considered good (Fielding and Bell 1997).

We assessed AUC scores secured by the ensemble model to evaluate the model performance for $V$. dubia, and the relative influence of the predictors on habitat projections. The model first projected probability of distribution of the species for the entirety of Gallatin County; we then arbitrarily created a $250 \mathrm{~m}$ buffer along both sides of the road network for each climate scenario. The general consensus is that the distance of 250 $\mathrm{m}$ from the roadside can be heavily affected by human disturbance. Within the $250 \mathrm{~m}$ buffer of roads and the entire Gallatin County, we categorized probability or habitat suitability of $V$. dubia into two categories, suitable habitat with a value $>0.51$ and unsuitable with a value $<0.51$ for each climate scenario.

\section{Land ownership classifications}

We quantified the projected area covered by $V$. dubia across different land use land cover classes using the National Land Cover Data (NLCD) for 2016 (Dewitz 2019). The NLCD is a raster dataset of $30 \mathrm{~m}$ resolution with 16 Land Use Land Cover (LULC) classes for conterminous USA. We regrouped the NLCD data into the five new land use classes: Developed (developed open space, developed low intensity, developed medium intensity, and developed high intensity), forest (deciduous forests, evergreen forests and mixed forests), shrubland, grassland, and agriculture (hays/pasture and cultivated) area. The NLCD "Open Water and Wetlands" cover classes were not considered during the analysis, and barren was removed due to low 
representation $(<0.002 \%)$. Reclassified land classes were overlaid on the projected roadside habitat map of $V$. dubia, and we estimated the projected infested area across each land use categories.

\section{Results}

The variables that were retained in the species distribution models for $V$. dubia relate to its growth pattern and include precipitation, PET, relative humidity and solar radiation for various spring through autumn months (Fig. 2). Four months were important for precipitation (March, May, July and September) (April and June were excluded due to correlations), whereas higher PET, lower relative humidity and higher solar radiation were important early and mid-summer (May and July), along with solar radiation in September. Other important variables included vapor pressure deficit in May, maximum temperature in July and available soil water holding capacity.

Model ensemble output showed excellent agreement in predicting observed distribution of $\mathrm{V}$. dubia across Gallatin County with AUC value of 0.98 . Twenty percent of the available road corridor is currently suitable habitat for V. dubia (Fig. 3.), covering $243 \mathrm{~km}^{2}$ (Fig. 4). Ventenata dubia is projected to increase under both scenarios, but most under RCP8.5 (Fig. 3). The roadside area suitable for $V$. dubia is projected to dramatically increase, by $239 \%\left(822 \mathrm{~km}^{2}\right)$ under RCP4.5 and $302 \%\left(974 \mathrm{~km}^{2}\right)$ under RCP8.5 (Fig. 4, 5). This equates to $67 \%$ and $79 \%$ of the road corridor being projected as suitable for $V$. dubia under RCP4.5 and RCP8.5 climate scenarios in 2040, respectively (Fig. 3). Across the entire Gallatin County, the model projected 1,371 km² suitable habitat range of $V$. dubia under current climate (Fig. 4) which is $20 \%$ of the total county (Fig. 3). Projected habitat of $V$. dubia was always greater under high emission scenario RCP 8.5 compared to RCP 4.5 (Figs. 3, 4 and 5). Among future climates, the model again projected the greatest increase in suitable $V$. dubia habitat at $240 \%\left(4,669 \mathrm{~km}^{2}\right)$ under RCP 8.5 compared with $79 \%\left(3,116 \mathrm{~km}^{2}\right)$ under RCP4.5 for the year of 2040.

Based on national land cover data, the land adjacent to the road corridor consists mainly of forest ( $43 \%$, $\left.2,875 \mathrm{~km}^{2}\right)$, followed by shrubland $\left(24 \%, 1589 \mathrm{~km}^{2}\right)$, then equal amounts of agricultural and grasslands $\left(14 \%, 95 \mathrm{~km}^{2}\right.$ each) with developed land representing only $3 \%\left(191 \mathrm{~km}^{2}\right)$ of the county. Under current climate conditions the model predicted greatest cover of $\mathrm{V}$. dubia in shrubland (37\%), similar amounts in forest (32\%) and developed land (31\%), and less but again similar amounts in grassland $(18 \%)$ and agriculture $(17 \%)$ (Tables 1; Figs. 5 and 6). V. dubia expansion across different land class types of Gallatin County was projected to be higher under RCP8.5 compared to that of RCP4.5. The projected expansion of V. dubia was greatest on agricultural land $\left(425 \% ; 860 \mathrm{~km}^{2}\right)$ and $\left.\left(484 \% ; 956 \mathrm{~km}^{2}\right)\right)$ and grassland $\left(278 \% ; 657 \mathrm{~km}^{2}\right)$ and $\left(442 \% ; 943 \mathrm{~km}^{2}\right.$ ) under RCP4.5 and RCP8.5, respectively (Table 2; Fig. 6). The least increase was in forest, where only a $60 \%$ increase was predicted under RCP4.5 (Table 2; Fig. 6). 
Table 1

Percentage change in projected suitable area of Ventenata dubia in different land use types from current to 2040 under RCP4.5 and RCP8.5 scenarios for Gallatin county, Montana.

\begin{tabular}{|llllll|}
\hline & Developed & Agriculture & Grassland & Shrubland & Forests \\
\hline Current & 31 & 17 & 18 & 37 & 32 \\
RCP4.5 & 196 & 425 & 278 & 99 & 60 \\
RCP8.5 & 226 & 484 & 442 & 169 & 207 \\
\hline
\end{tabular}

Table 2

Current and projected area of Ventenata dubia $\left(\mathrm{km}^{2}\right)$ land adjacent to road corridors in Gallatin County, Montana, under RCP4.5 and RCP8.5 climate change projections for 2040. LULC = Land Use Land Cover

\begin{tabular}{|llll|}
\hline LULC & Current & RCP4.5 2040 & RCP8.5 \\
\hline Developed & 59 & 173 & 191 \\
\hline Agriculture & 164 & 860 & 956 \\
\hline Grassland & 174 & 657 & 943 \\
\hline Shrubland & 581 & 1158 & 1560 \\
Forests & 930 & 1491 & 2850 \\
\hline
\end{tabular}

\section{Discussion}

Coupling our current knowledge of $V$. dubia infestation locations with environmental factors allowed us to create predictive habitat suitability maps that identified areas at high risk of invasion in Gallatin County, Montana, USA. Our modeling approach projected the extent of habitat suitability of $V$. dubia under different climate scenarios across the road network and the entire county. The model ensemble showed excellent model performance using AUC model evaluation metrics, providing an accurate fit to the current distribution of $V$. dubia in Gallatin County. The ensemble modeling approach we adopted here avoids predictive variability associated with single models, because ensemble-forecasting generates a consensus prediction by combining the predictions from multiple techniques (Araújo and New 2007). The occurrence of $V$. dubia is most strongly associated with growing season through fall precipitation (wetter March, May, July and September), early and mid-summer (May and July) potential evapotranspiration, relative humidity and solar radiation, with September also being important for solar radiation; in addition May vapor pressure deficit, July maximum temperature and available soil water holding capacity were important. These variables explained most of the variation in distribution of $V$. dubia across our study area and relate to the species' lifehistory (Wallace et al. 2015). V. dubia is a fall germinating annual species, and in our region precipitation and warmth are important for germination in September. The species then overwinters in a dormant state, often protected from thermal extremes by snow, and starts to grow again in spring when increasing solar gain 
melts the snow and recharges the soil moisture, and spring and early summer climate variables support growth and reproduction.

The expansion of non-native plant populations with time is primarily associated with climate and other environmental filters (Averett et al. 2016). Understanding which climate variables are most important for individual species provides the capacity to model how a species' distribution will alter as our climate continues to change. Southwest Montana is projected to increase in average temperature by mid-century (1.5 and $2.5 \mathrm{C}$ for RCP4.5 and RCP8.5, respectively), and get wetter annually (13-19 mm and 19-25mm for RCP4.5 and RCP8.5, respectively) but have drier summers (Whitlock et al. 2017). In our study, the changing climate scenarios both predicted increases in V. dubia, though more so with RCP8.5 than RCP4.5. The projected increases in $V$. dubia were greater along the road corridor than county-wide. Among the land class types, agriculture land and grassland were highly likely to be infested by $V$. dubia, and grasslands were much more impacted under the RCP8.5 than RCP4.5 scenario. While road corridors are their own ecosystem due to their construction and maintenance, they are generally vegetated by perennial grasses, with some forbs and low shrubs. Thus, the roadside vegetation is most similar to grasslands in our county, potentially explaining why the roadside increase is similar to adjacent grasslands and greater than the entire county predictions (Gallatin $-46 \%$ and $68 \%$ vs Road $-67 \%$ and $79 \%$ under RCP 4.5 and RCP 8.5 , respectively).

Invasive species can be transported and spread unintentionally to new habitats along road corridors faster than they can spread through primary dispersal (Adhikari et al. 2020; Hulme 2009; Rew et al. 2018). The fact that our models showed $20 \%$ of the roadsides are currently suitable for $V$. dubia and that suitability increases in the future supports the hypothesis that road corridors are strong conduits for dispersal and that roadside management practices provide suitable gaps for new seed establishment. As the number of vehicles in Gallatin County and the entire state of Montana increase (Montana Department of Transportation, 2021), a rapid expansion of $V$. dubia is highly likely. Because seeds will be spread along the road corridor, they will also then move into adjacent lands where environmental filters are still suitable for $V$. dubia. Our models suggest that agricultural lands and grasslands will become more suitable as the climate changes, and where these habitats are proximal to busy highways or higher road density, there is likely to be more successful invasion.

Documented impacts of $V$. dubia are limited but noteworthy and highlight why management practices that prevent the invasion of $V$. dubia are desirable. Range, pasture, and natural areas impacted by $V$. dubia result in decreased plant community richness and diversity, low forage production, and potentially increased soil erosion due to the species' shallow root structure. Prather and Steele (2009) found that pasture, grass-hay and grasslands of north-central Idaho experienced a significant decline in forage production because of $V$. dubia invasion. In some situations, timing of hay harvest schedules had to be altered to avoid export losses due to $V$. dubia (Wallace et al. 2015). V. dubia has been associated with a decrease in plant species richness and diversity in the Palouse prairie and Canyon lands (Jones et al. 2020), and a decline in nesting success of insect-eating birds due to a loss of biodiversity in conservation lands in northern Idaho (Jones et al. 2018). Furthermore, $V$. dubia has displaced Bromus tectorum (cheatgrass or downy brome) in the Snake River Canyon grasslands of Idaho (Wallace et al. 2015). This is particularly alarming because $V$. dubia appears to be avoided by livestock, possibly due to its high silica content (Prather, Steele 2009). The silica content of $V$. 
dubia was found to be about $9 \%$ as compared to $3 \%$ for cheatgrass and $4 \%$ for Pseudoroegneria spicata (bluebunch) wheatgrass (Mangold, unpublished data). Fortunately, increases in $V$. dubia have not been observed after fire in Pacific Northwest temperate grasslands (Ridder et al. 2021) nor elsewhere. When rangelands become infested by species like $V$. dubia, however, the invasive, annual grasses create fine fuel for fire, and this fuel dries out quickly due to high surface-to-volume ratio, which in-turn, extends the fire season to earlier in summer (Rottler et al. 2015).

The economic cost of controlling invasive species is increasing every year. Montana alone spends millions of dollars to control invasive species annually. For example, the state spent \$12 million on control and management of noxious weeds in 2018 (Burch 2020). Ventenata dubia is a relatively new invader ( 30 years) in Montana. A guiding principle of integrated weed management is that addressing a species closer to the beginning of an invasion is more effective than waiting until later, when the species is widely distributed and well-established (Hobbs, Humphries 1995). This guiding principle is supported by the Montana Noxious Weed Management Plan (Montana Department of Agriculture 2017) where early detection is emphasized under the broad management goals of prevention, detection, and rapid response. Furthermore, as all habitats are not similar in terms of invasion susceptibility, measurements need to be taken to determine which habitats are more prone to invasion in order to develop the most effective management plan. The current study addresses this by improving our understanding of the potential spatial extent of V. dubia in Gallatin County under current and future climates and evaluating habitat preferences of the species. The fact that the road corridors are likely to become increasingly infested by $V$. dubia as the climate changes suggests an important first step in the management of this species will be periodic monitoring to 1) evaluate the efficacy of control strategies and b) search for new populations, preferably along the predicted suitability gradient (Rew et al. 2007). In this way the best control strategies can be determined and used, and if control strategies differ along the environmental suitability gradient, a more adaptive approach should be developed.

Searching for new populations can be prioritized by starting with the highest risk areas on the environmental suitability map, especially where they coincide with the highest risk land uses (agriculture, grassland), and continuing to lower risk areas as resources allow. Locating new populations along road corridors is vital as these populations will act as source populations, invading into adjacent land, particularly grasslands and agriculture.

Our results identified new habitats along the road corridor and in the adjacent land of Gallatin County that may be at risk of invasion by $V$. dubia. Montana and counties in adjacent states with high road density or busy highways are most at risk for new invasions along the road corridor, which may then spread into adjacent land. Road corridors in the state are already infested with many noxious weed species, some of which are also predicted to increase as the climate changes (Adhikari et al. 2020). Exactly how the invasive and native species will interact as the climate continues to change is unknown but should be considered (Crossman and Bass 2007; Crossman et al. 2011). However, not all species have equal potential to invade and all habitats are not equally threatened by invasion to the same degree (Lonsdale 1999). The degree of invasion in a particular habitat depends on the traits of invasive species, the environment of recipient habitat, and the propagule pressure with which invasive species are entering into the recipient habitat (Rejmánek et al. 2005). Our study highlights climate variables and land use-types most at risk to $V$. dubia invasion now 
and in the future, and these maps can be used to help prioritize monitoring and management of those populations that pose the greatest threat to habitats.

\section{Declarations}

\section{Conflict of interest:}

The authors declare no conflict of interests.

\section{Acknowledgements}

This project was funded by the Montana Noxious Weed Trust Fund (MDA grant 2019-012). Thanks to Eli Harmon, Lilly Sencenbaugh, Colter Komar, and Stacey Robbins who performed the road corridor survey and the Gallatin County Noxious Weed District for sharing their expertise and $V$. dubia location maps upon which our surveys were based upon. JMM and LJR are supported by the National Institute of Food and Agriculture, U.S. Department of Agriculture Hatch: MONB00359, MONB00363, respectively. No conflicts of interest have been declared.

Data availability statement: Data generated during this study can be available from the corresponding author on reasonable request.

\section{References}

1. Abatzoglou JT, Brown TJ (2012) A comparison of statistical downscaling methods suited for wildfire applications. Int J Climatol 32:772-780

2. Adhikari A, Hansen AJ, Rangwala I (2019a) Ecological water stress under projected climate change across hydroclimate gradients in the north central United States. Journal of Applied Meteorology Climatology 58:2103-2114

3. Adhikari A, Mainali KP, Rangwala I et al (2019b) Various measures of potential evapotranspiration have species-specific impact on species distribution models. Ecol Model 414:108836

4. Adhikari A, Rew LJ, Mainali KP et al (2020) Future distribution of invasive weed species across the major road network in the state of Montana, USA. Reg Environ Change 20:1-14

5. Araújo MB, New M (2007) Ensemble forecasting of species distributions. Trends Ecol Evol 22:42-47

6. Averett JP, McCune B, Parks CG et al (2016) Non-native plant invasion along elevation and canopy closure gradients in a middle Rocky Mountain ecosystem. PloS one 11:e0147826

7. Breiman L (2017) Classification and regression trees. Routledge

8. Burch D (2020) State agency and county weed district biennial noxious weed report. https://agr.mt.gov/Portals/168/Documents/Weeds/Biennial\%20Report/20182019_Biennial_Noxious_Weed_Report.pdf?ver=2020-07-28-094717-023 Accessed: 05/05/2021 2020 
9. Crossman ND, Bass DA (2007) Application of common predictive habitat techniques for post-border weed risk management. 14:213-224

10. Crossman ND, Bryan BA, Cooke DA (2011) An invasive plant and climate change threat index for weed risk management: Integrating habitat distribution pattern and dispersal process. 11:183-198

11. Dewitz J (2019) National Land Cover Database (NLCD) 2016 Products. U.S. Geological Survey data release, https://doi.org/10.5066/P96HHBIE

12. Dormann CF, Mcpherson JM, Araújo MB et al (2007) Methods to account for spatial autocorrelation in the analysis of species distributional data: a review. Ecography 30:609-628

13. Dostálek J, Frantík T, Šilarová V (2016) Changes in the distribution of alien plants along roadsides in relation to adjacent land use over the course of 40 years. Plant Biosystems-An International Journal Dealing with all Aspects of Plant Biology 150:442-448

14. Fielding AH, Bell JF (1997) A review of methods for the assessment of prediction errors in conservation presence/absence models. Environ Conserv 24:38-49

15. Franklin J (2013) Species distribution models in conservation biogeography: developments and challenges. Divers Distrib 19:1217-1223

16. Gelbard JL, Belnap J (2003) Roads as conduits for exotic plant invasions in a semiarid landscape. Conserv Biol 17:420-432

17. Guisan A, Thuiller W (2005) Predicting species distribution: offering more than simple habitat models. Ecol Lett 8:993-1009

18. Harvey AJ, Mangold JM (2019) Ventenata. In. https://store.msuextension.org/publications/AgandNaturalResources/mt201810AG.pdf Accessed: 05/01/2021 2021

19. Harvey AJ, Rew LJ, Prather TS et al (2020) Effects of Elevated Temperature and CO2 Concentration on Seedling Growth of Ventenata dubia (Leers) Coss. and Bromus tectorum L. Agronomy 10:1718

20. Hastie T, Tibshirani R, Buja A (1994) Flexible Discriminant Analysis by Optimal Scoring. 89:1255-1270

21. Hobbs RJ, Humphries SE (1995) An integrated approach to the ecology and management of plant invasions. Conservation biology 9:761-770

22. Hulme PE (2009) Trade, transport and trouble: managing invasive species pathways in an era of globalization. Journal of applied ecology 46:10-18

23. Jones LC, Davis C, Prather TS (2020) Consequences of Ventenata dubia 30 years postinvasion to bunchgrass communities in the Pacific Northwest. Invasive Plant Science Management 13:226-238

24. Jones LC, Norton N, Prather TS (2018) Indicators of ventenata (Ventenata dubia) invasion in sagebrush steppe rangelands. Invasive Plant Science Management 11:1-9

25. Lonsdale WM (1999) Global Patterns of Plant Invasions and the Concept of Invasibility. 80:1522

26. Lugo AE, Gucinski H (2000) Function, effects, and management of forest roads. For Ecol Manage 133:249-262

27. Magness DR, Huettmann F, Morton JM (2008) Using random forests to provide predicted species distribution maps as a metric for ecological inventory \& monitoring programs. Applications of 
computational intelligence in biology. Springer, pp 209-229

28. McDougall KL, Lembrechts J, Rew LJ et al (2018) Running off the road: roadside non-native plants invading mountain vegetation. Biol Invasions 20:3461-3473

29. Miller DA, White RA (1998) A conterminous United States multilayer soil characteristics dataset for regional climate and hydrology modeling. Earth interactions 2:1-26

30. Montana Department of Agriculture (2017) Montana noxious weed management plan. https://agr.mt.gov/Portals/168/Documents/NWTF/MT\%20Noxious\%20Weed\%20Management\%20Plan\%20Update\%202017.pdf. Accessed May 2021

31. Montana Department of Transportation (MDT) (2021) Symposium on Ecology, Management and Restoration of Intermountain Annual Rangelands, Boise, ID

32. Moss RH, Edmonds JA, Hibbard KA et al (2010) The next generation of scenarios for climate change research and assessment. Nature 463:747-756

33. Northam FE, Callihan RH (1992) New woody grasses associated with downy broom. In. https://www.fs.fed.us/rm/pubs_int/int_gtr313/int_gtr313_211_212.pdf Accessed: 05/01/2021 2021

34. Olden JD, Lawler JJ, Poff NL et al (2008) Machine Learning Methods Without Tears: A Primer for Ecologists. Q Rev Biol 83:171-193

35. Prasad AM, Iverson LR, Liaw A (2006) Newer Classification and Regression Tree Techniques: Bagging and Random Forests for Ecological Prediction. Ecosystems 9:181-199

36. Prather T, Steele V (2009) Ventenata control strategies found for forage producers. University of Idaho Extensions: Idaho Impact Statements:1-2

37. Rejmánek M, Richardson DM, Higgins SI et al (2005) Ecology of invasive plants: state of the art. Scopescientific committee on problems of the environment international council of scientific unions 63:104

38. Rew LJ, Brummer TJ, Pollnac FW et al (2018) Hitching a ride: Seed accrual rates on different types of vehicles. J Environ Manage 206:547-555

39. Rew LJ, Lehnhoff EA, Maxwell BD (2007) Non-indigenous species management using a population prioritization framework. 87:1029-1036

40. Ridder LW, Perren JM, Morris LR et al (2021) Historical Fire and Ventenata dubia Invasion in a Temperate Grassland. Rangeland Ecology Management 75:35-40

41. Rottler CM, Noseworthy CE, Fowers B et al (2015) Effects of conversion from sagebrush to non-native grasslands on sagebrush-associated species. Rangelands 37:1-6

42. Seipel T, Kueffer C, Rew LJ et al (2012) Processes at multiple scales affect richness and similarity of non-native plant species in mountains around the world. Glob Ecol Biogeogr 21:236-246

43. Šerá B (2010) Roadsides function as halophyte habitats in the landscape. IV Czech-Slovak Scientific Conference Transport, Health and Environment “. Blansko, November 2-3, 2010. Brno: Transport Research Centre, 2010, 242 pp. pp. 149

44. Spellerberg I (1998) Ecological effects of roads and traffic: a literature review. Glob Ecol Biogeogr 7:317333 
45. Taylor K, Brummer T, Taper ML et al (2012) Human-mediated long-distance dispersal: an empirical evaluation of seed dispersal by vehicles. Divers Distrib 18:942-951

46. Thuiller W, Georges D, Engler R (2016) biomod2: Ensemble platform for species distribution modeling. R package version 3:1-64

47. USClimate (2021) U.S. Climate Data. In.

https://www.usclimatedata.com/climate/bozeman/montana/united-states/usmt0040 Accessed: 05/02/2021

48. Vakhlamova T, Rusterholz H-P, Kanibolotskaya $Y$ et al (2016) Effects of road type and urbanization on the diversity and abundance of alien species in roadside verges in Western Siberia

49. Wallace JM, Pavek PL, Prather TS (2015) Ecological characteristics of Ventenata dubia in the Intermountain Pacific Northwest. Invasive Plant Science Management 8:57-71

50. Whitlock C, Cross W, Maxwell B et al (2017) Montana climate assessment. Montana State University, Bozeman, MT, USA

\section{Figures}




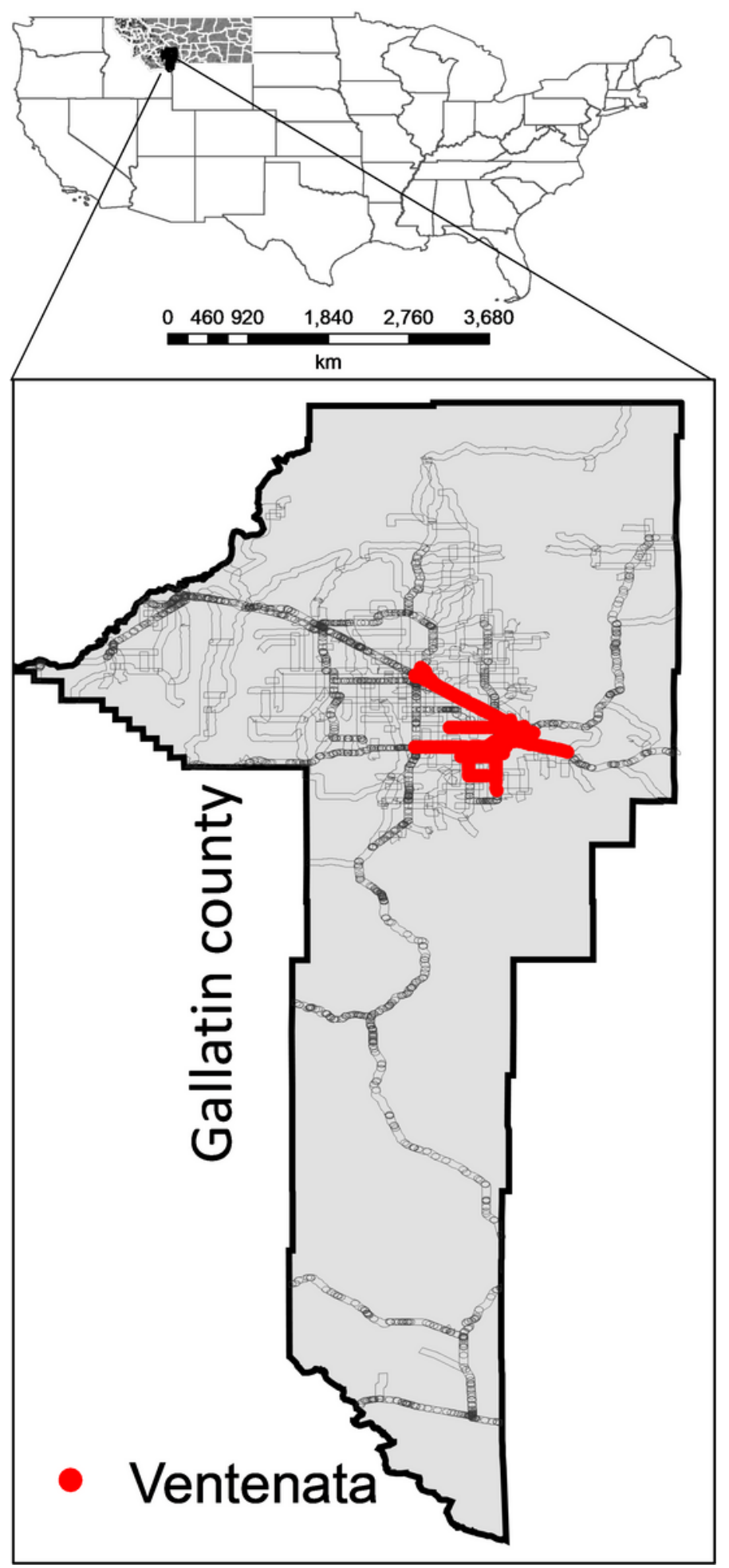

Figure 1

Map of study area showing presence of Ventenata dubia (red) along surveyed major and main roads (black open circles) in Gallatin County, Montana, USA. The presence and absence records of V. dubia were collected along the roadsides during 2019-2020 surveys. 


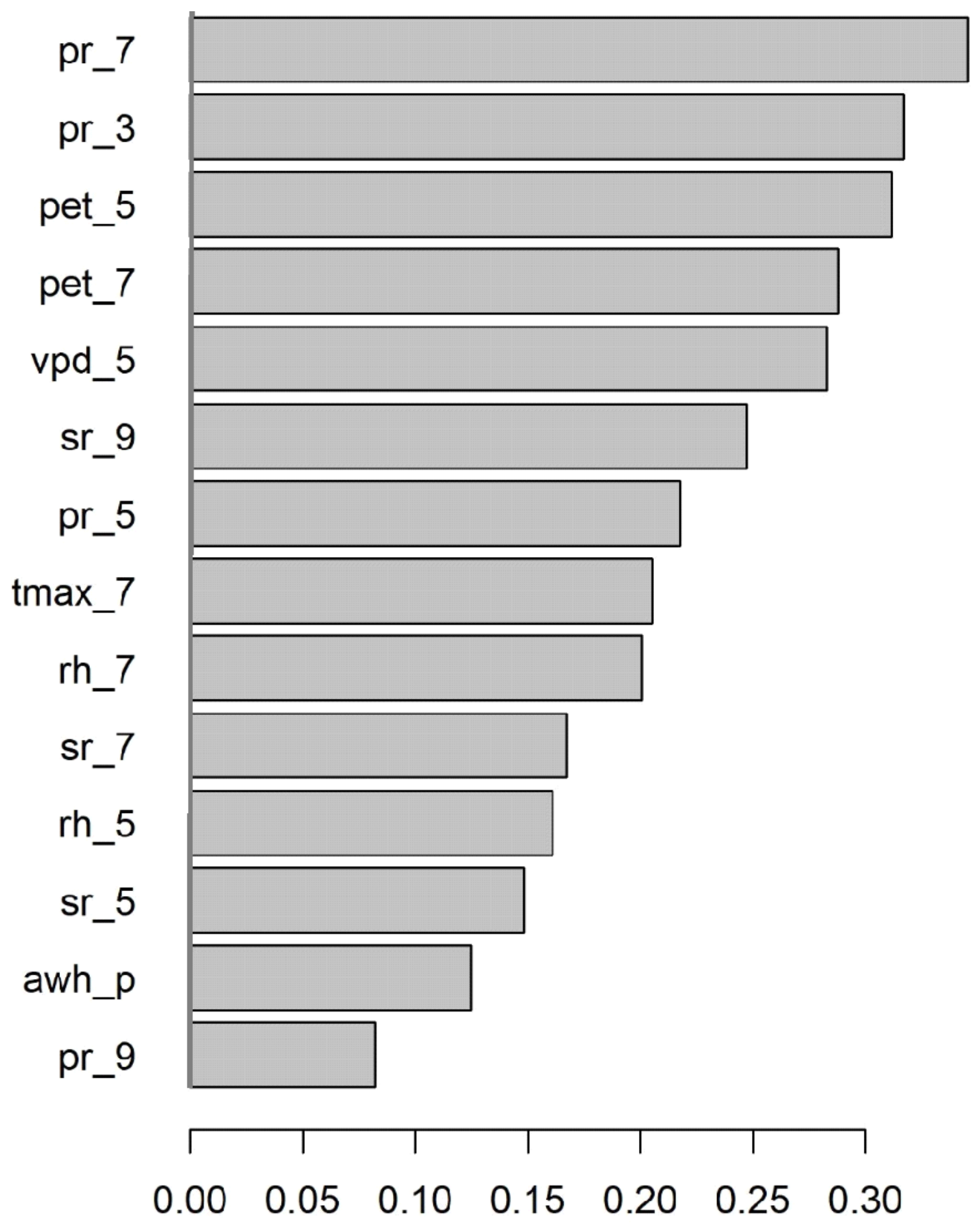

Figure 2

Relative importance of climate and environmental variables for Ventenata dubia. Abbreviation - awh_p: available soil water holding capacity, vpd: vapor pressure deficit, pet: potential evapotranspiration, sr: solar radiation, pr: precipitation, tmax: maximum temperature, rh: relative humidity. The number at the end of each variable represents the respective month (e.g. tmax_7: July maximum temperature; sr_7: July solar radiation) 


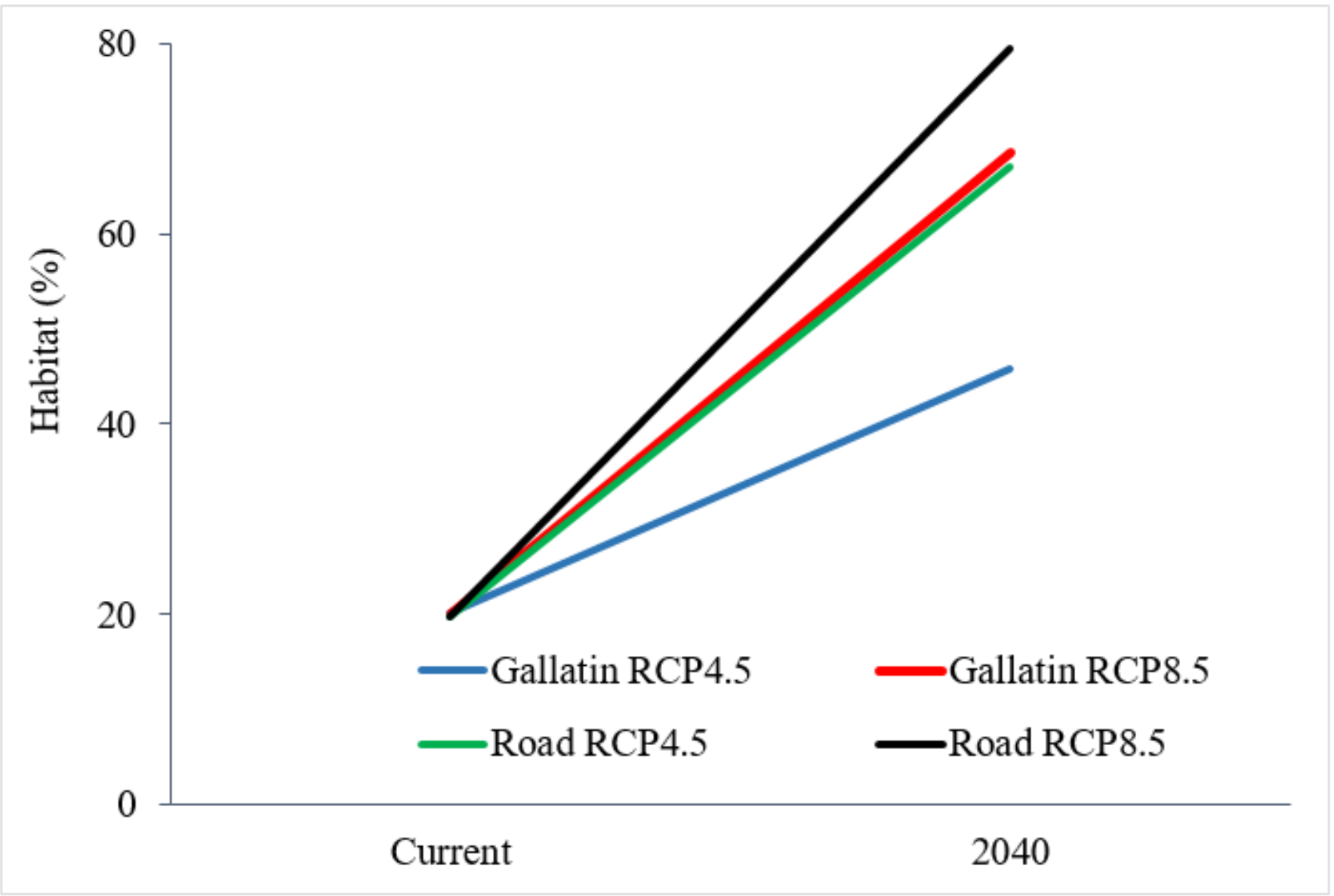

\section{Figure 3}

Projected habitat percent of Ventenata dubia across road networks and Gallatin County, Montana, USA, from current to future climate change scenarios RCP4.5 and RCP8.5. 


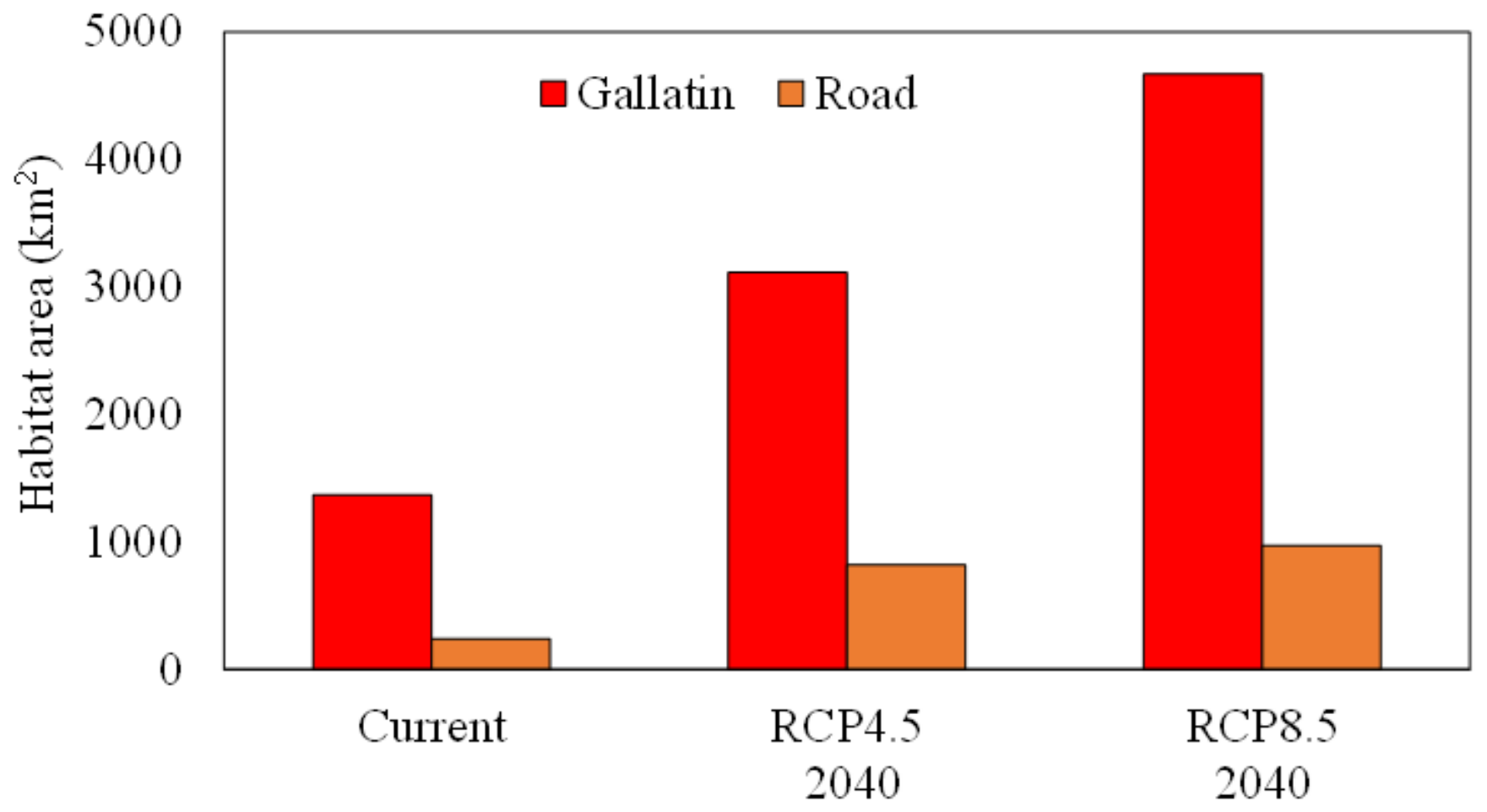

Figure 4

Projected current and future habitat area of Ventenata dubia for the road corridor (1,226 km2 total) and Gallatin County (6,829 km2 total), Montana, USA, under future climate change scenarios RCP4.5 and RCP8.5.

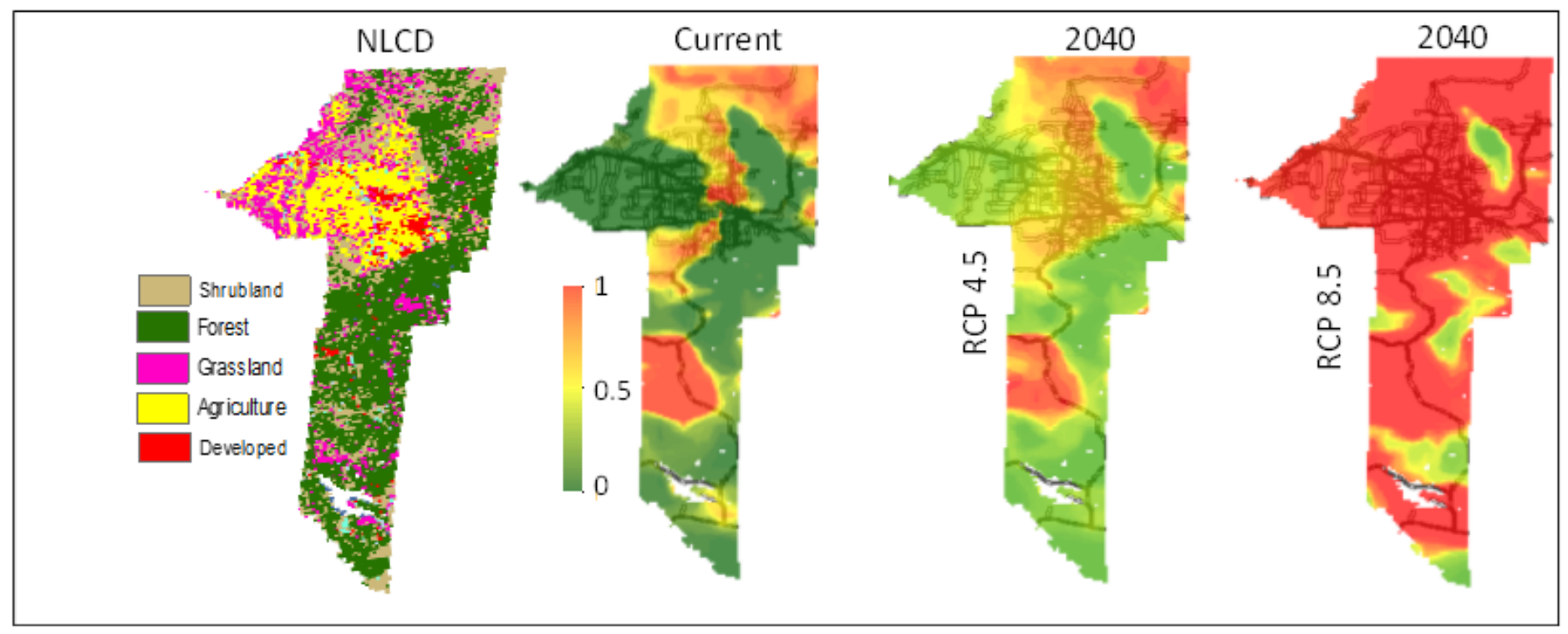

\section{Figure 5}

Presence of different land use types in Gallatin County, Montana, USA, and probability of current and future distribution of Ventenata dubia across the county under climate change scenarios RCP4.5 and RCP8.5 for the year 2040. Maps of land use class types used NLCD, 2016 cover data. 


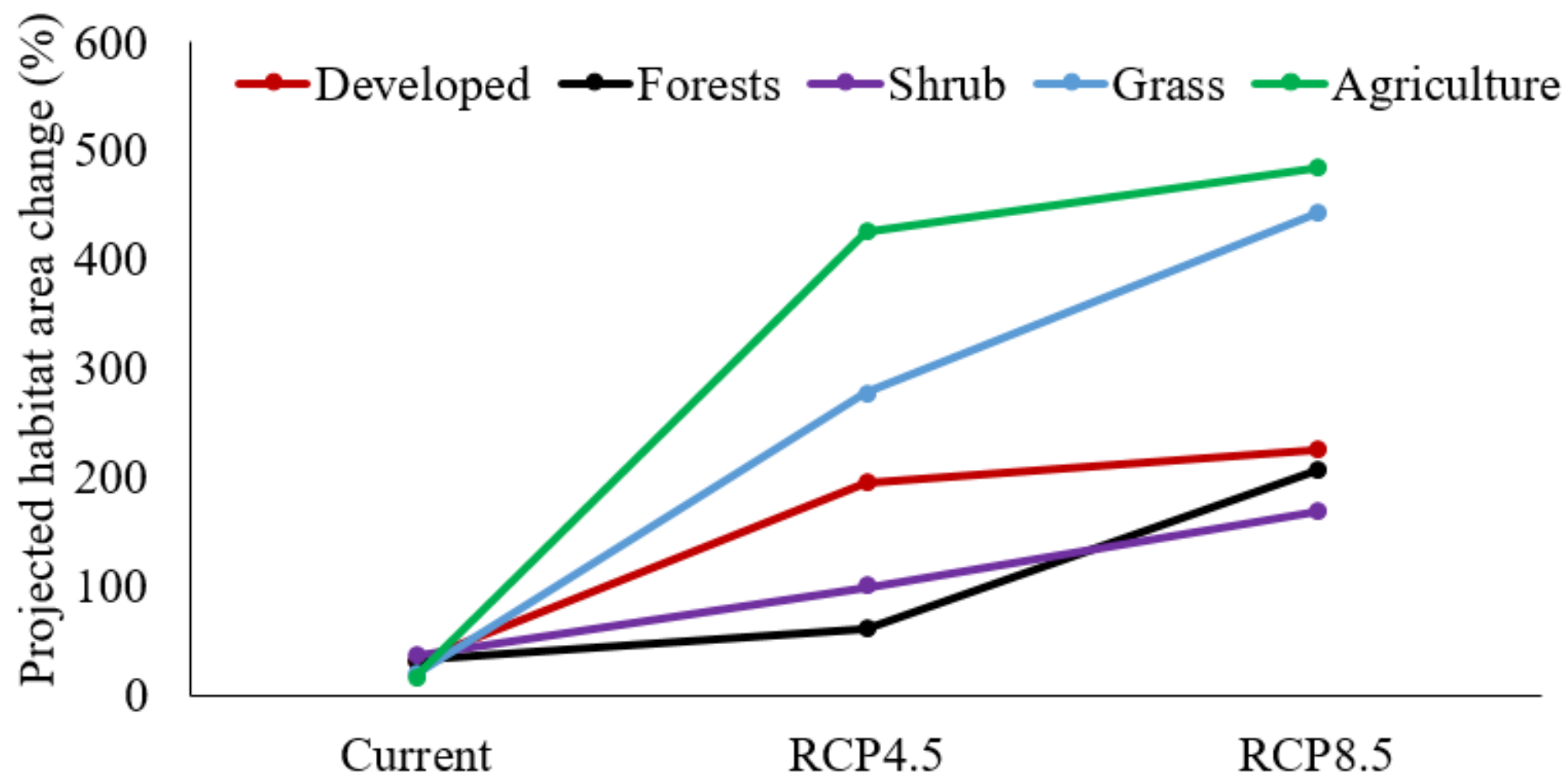

Figure 6

Projected Ventenata dubia habitat change (\%) for the different land class types by 2040 under RCP4.5 and RCP8.5. 